\title{
Proceedings
}

\section{Booktrailers and Bookémon Go! BYOD and QR in Primary Education ${ }^{+}$}

\author{
Francisco Manuel González Galán \\ Consejería de Educación, Junta de Extremadura, 06800 Mérida, Spain; franciscogongal@gmail.com; \\ Tel.: +34-678-54-79-34 \\ + Presented at the 2nd Innovative and Creative Education and Teaching International Conference \\ (ICETIC2018), Badajoz, Spain, 20-22 June 2018.
}

Published: 5 November 2018

\begin{abstract}
Both Booktrailers and Bookémon Go! consist of a two-in-one innovation projects carried out in a Primary school in Mérida (Spain) with the main aims of promoting books reading and fostering books loan at the school library using smartphones or tablets to search the web, record their reviews, generate QR codes, create and publish their texts online and web designing; and to work collaboratively in a group according to assigned roles.
\end{abstract}

Keywords: Bookémon; booktrailers; QR; BYOD; smartphones; primary; reading; library

\section{Introduction}

In the last two years a huge effort has been made in our school to build a library from scratch, one that invites reading and enjoyment. Thus, honoring the archaeologist that gives its name to our school, Maximiliano Macias, we have decorated it with archaeological details turning it into a Mayan temple. We also have our own mascot, the archaeologist and explorer Maxi Jones.

Through this project we try to encourage our students to read and loan books in a fun way, close to their interests.

Taking advantage of the current Youtubers boom and the Pokémon Go! App for mobiles, we have created collaboratively our Videoreseñas (Booktrailers) and our game Bookémon Go! projects in the group of Year 6 during the academic year 2016-17, with the main objective of encouraging our boys and girls to read thanks to videos and games.

My Year 6 students are children who use smartphones, tablets and computers every day. They connect to the world wide web, either to watch videos on YouTube, interact on social networks such as Instagram or Whatsapp or to play video games online.

In the recent years, "youtubers" have become idols for children and young people, with millions of followers all over the planet. Our students enjoy their videos up to the point of copying them, creating their own YouTube channels to share their everyday life online.

As a true defender of active learning, I believe that 21st century education should be studentcentred. Kids must lead their learning. This aspect must be reinforced by a total integration of educational technologies in the day to day of the school. In Bookémon Go! we use innovative elements in the world of education such as smartphones and augmented reality from QR codes.

\section{Discussion}

\subsection{Objectives and Contents}

The objectives that we have set for the development of the project have been: 
- $\quad$ Engaging students in reading.

- Develop key competences: linguistic competence, digital competence, cultural awareness and expression, entrepreneurship, and learning to learn.

- Reinforce creativity while respecting intellectual property.

- Improve personal autonomy.

- Enhance collaborative work as a team.

- Foster a critical spirit.

- Develop spatial orientation and attention.

The contents developed in this project are:

- Comprehension and oral and written expression, in the creation of the biography of each Bookémon and booktrailer.

- Responsible use of digital applications that have helped develop this work.

- Acceptable and safe use of tablets and smartphones.

- Collaborative and cooperative team work.

- Social entrepreneurship. This project has motivated other students in the school to read more and visit the library more often.

\subsection{Procedure}

\subsubsection{Booktrailers}

It consists of the process of recording video reviews, also called booktrailers, of books from our library [1]:

- In pairs, they select a book from the library.

- After they finish reading it, they complete a written review stating title, author, publisher, plot and their personal opinion of that book.

- Next, they rehearse the video review of the book in a place of the school of their choice (library, classrooms, playground, corridors...).

- They record themselves with their own device without extra help, enhancing creativity and using the tablet or the class smartphone.

- They generate the QR code of the YouTube link from their videoreview, we print it and paste it on the inner flap of all the copies of this book that can be found in the school library.

- It is time to share our videos or booktrailers in a collaborative wall created with the digital tool Padlet (https://goo.gl/WLgvqs).

- Finally, we publish the process and result in the class blog and we spread it through social media Twitter, Facebook, Pinterest and Google+ (https://goo.gl/VgCWAV).

\subsubsection{Bookémon Go!}

What is a Bookémon? If you ever come to Maximiliano Macias Primary school you should know in advance that there are some creatures, some of them kind, others a bit naughty, hidden in any part, any corner of the place, either inside a building or secretly in the yard. They are called Bookémons and have been born out of the imagination of boys and girls of Year $6 \mathrm{~B}$ to pass on their love for books to all the students at school [2]

This second part of the project consisted of the next steps:

1. We organized ourselves in teams of four students with defined roles voluntarily chosen by themselves: artists, editors, computer experts and coordinators.

2. In a cooperative way, we created three Bookémon per team. Then, after discussing in the group, the artists design the draft of the Bookémon. They performed color tests and photographed the final design with the class smartphone. 
3. Writers wrote about their origin or place where they live in the school. They also described their features and/or their likes, always ending with the Bookémon's favorite book that will be recommended for us to read from our library catalogue.

4. Computer scientists create a hidden website for each Bookémon with Google Sites tool. They publish all the above (design and text) include the video review of the book this Bookémon recommend us along with its cover.

5. Coordinators are in charge of directing and collaborating with the members of their team. They also agree with other groups what books (and videos) will be worked to avoid duplications.

6. We generated the QR codes of the fifteen Bookémons designed. These QR codes link to websites where the creatures are hidden (https://goo.gl/OnKthU). As these websites are secret they cannot be accessed without using the specific QR code. That's why the Bookémons are hidden.

7. QR codes are generated online from free sites such as QRCODE.es and are pasted into an online collaborative document generated with Google Documents. From there we can print all the QR codes, cut them out and laminate them.

8. We release our Bookémons around and about the playground of our school and play to hunt them along with other groups. To do so we use smartphones or tablets and any free QR code reader application (such as QR Droid, QR Code Reader ...).

9. Once a Bookémon is hunt and captured we collect it in an album that we have also designed: the album of Master of Bookémon.

\section{Evaluation}

On one hand, assessment of the videoreviews project is done with a rubric where each item relates to a stage of the process carried out by the students (this rubric can be downloaded and printed). In addition to evaluating the steps, two items are added to assess collaborative work and personal satisfaction.

It takes place in class. Firstly, a self-evaluation is carried out where each student reflects on their involvement in the phases of the project and evaluates himself/herself accordingly. Secondly, they evaluate another partner based on the same rubric. Children work out the average of the sum of the two results obtained and a rule of three is calculated to obtain a grade from 1 to 10 , which will become part of the assessment of the subject.

Another aspect to remark is the analysis we do of booktrailers in the classroom, highlighting their strengths and the aspects likely to be improved, in small groups initially to reach a consensus in a large group.

On the other hand, Bookémon Go! final evaluation is carried out continuing the collaborative mind. In small groups students discuss which aspects they consider most important to evaluate. Groups then present their ideas one by one to the rest of the class in order to reach a consensus and develop the evaluation rubric.

It goes through a double process: first a self-evaluation and then a coevaluation $1+1$, where each student evaluates a partner and is, at the same time, evaluated by another partner. CoRubrics online software is used as the evaluation tool. The rubric designed by the kids is pasted into a spreadsheet in Google Drive, and then transformed into a form. Students receive the direct link to this form and complete the online rubric from their own device (tablet or netbook) in the class.

\section{Conclusions}

Varied key competences are worked within the Language area:

- Linguistic competence (CCL) when reading of the book, writing of the review, rehearsal and video recording, when writing the text about the Bookémon, in the debate and in the interaction within the group in different reading and communication processes.

- Linguistic competence (CCL) when reading of the book, writing of the review, rehearsal and video recording, when writing the text about the Bookémon, in the debate and in the interaction within the group in different reading and communication processes. 
- Digital competence (CD) when using devices such as tablets and smartphones connected to the Internet, when generating $\mathrm{QR}$ codes, recording videoreviews, transfering designs and texts to the websites, inserting videos and book covers, working on Google Drive, and designing the web collaboratively with Google Sites.

- Learning to learn competence when they must solve technological or organizational issues.

- Entrepreneurship when students decide collaboratively the setting for the booktrailer, the device to use, assign roles, choose the form of presentation, agree on the name, design and features of Bookémon or propose ideas for project improvement, etc.

- Finally, cultural awareness and expressions are enhanced by having freedom when showing their whole creativity in the making of the video review (interview, drama, news...).

Emotionally, it is a project that uplifts both students and teacher. Our children at school are not used to having freedom in decision-making when carrying out activities and projects, so given the chance, they always surprise us and exceed our expectations, however high they may be. Similarly, freedom of movement throughout the school foster their autonomy and creativity when they are outside classroom walls.

When they must work collaboratively they just need a little guidance. Soon fellowship appears and each one gives his/her best to achieve their goals.

Student-centred methodology boosts autonomy as well as creativity. The initial objective of encouraging reading is overflowed by simultaneous achievements such as group cohesion, integration of shy students and increase of self-esteem as each child plays an important role within the group and, therefore, is a relevant character of the project from the very first moment.

Author Contributions: F.M.G.G. conceived, designed, performed the experiments and wrote the paper.

Acknowledgments: The author would like to acknowledge Consejería de Educación of Junta de Extremadura for the Premio a la Innovación Educativa "Joaquín Sama 2017" award to this project. No funds for covering the costs to publish in open access were received.

Conflicts of Interest: The author declares no conflict of interest. The founding sponsors had no role in the design of the study; in the collection, analyses, or interpretation of data; in the writing of the manuscript, and in the decision to publish the results.

\section{References}

1. Videoreseñas o Booktráilers en el aula de Primaria. Francisco Manuel González Galán. Available online: https://enmarchaconlastic.educarex.es/236-emtic/fomento-de-la-lectura/2995-videoresenas (accessed on 1 June 2018).

2. Atrapa al Bookémon Go! Estrategias de Fomento de la Lectura con Gamificación. Francisco Manuel González Galán. Available online: https:/enmarchaconlastic.educarex.es/251-nuevo-emt/juegos-ygamificacion/3014-bookemon (accessed on 1 June 2018).

(C) 2018 by the author. Licensee MDPI, Basel, Switzerland. This article is an open access article distributed under the terms and conditions of the Creative Commons Attribution (CC BY) license (http://creativecommons.org/licenses/by/4.0/). 